\title{
PACKAGE PERFORMANCE TESTING OF DANGEROUS GOODS IN HIGH ALTITUDE SHIPMENTS
}

By S. Paul Singh, Ph.D., Professor, Gary J. Burgess, Ph.D., Professor Jagjit Singh, Ph.D., Research Associate Of the School of Packaging, Michigan State University, East Lansing MI 48824

\section{Contact author:}

S. Paul Singh

130 Packaging Building

Michigan State University,

East Lansing, MI 48824-1223

Tel (517) 355-7614,

Fax (517) 353-8999,

e-mail: singh@msu.edu

Keywords: Packaging, Air Transport, Dangerous Goods, High Altitude, Leaks, Torque, Testing

\section{Abstract}

This paper discusses the impact of high altitude shipments on package integrity. High altitude shipments are encountered when trucks travel over high mountain passes or when cargo and feeder aircraft transport packages in non-pressurized or partially-pressurized cargo holds. Both these types of transport methods will result in severe changes in pressure and temperature conditions as compared to packages being transported close to sea-level. The testing of packages under these conditions is critical since package integrity may be compromised. The current shipping tests performed in test labs do not account for pressure changes and vibration together. This study showed that combination packages for dangerous goods and hazardous materials that are tested to existing $U N$, $I C A O$ and US DOT requirements are limit$e d$, and can result in significant number of leaks. Testing under combined vibration and pressure changes is necessary.

\section{INTRODUCTION}

The Federal Aviation Administration has observed an increase in the number of package failures of dangerous goods in commercial and cargo aircraft over the past three years ${ }^{1,2}$. Figure 1 shows the different classifications of products that had package related failures. Table 1 shows the cause of failure by package type. For plastic and metal packages, failure of the closure/seal accounted for about $65 \%$ of failures. For glass containers, drops account for about half, with seal failures down to $23 \%$.

In addition to the above findings, the United Parcel Service presented a study to the American Society of Testing and Materials (ASTM) describing the conditions that packages experience in the single parcel shipping environment ${ }^{3}$. The study resulted in the following key observations as described in ASTM D6653-01:

- Cargo air jets are typically pressurized to about $75 \mathrm{kPa}$, which is normal atmospheric pressure at an altitude of $2,438 \mathrm{~m}(8,000 \mathrm{ft})$. Temperature is maintained at approximately 20 to $23^{\circ} \mathrm{C}\left(68\right.$ to $\left.74^{\circ} \mathrm{F}\right)$

- Packages transported on the ground may experience altitudes as high as $3,658 \mathrm{~m}(12,000 \mathrm{ft})$ when shipped over certain mountain passes, especially in Colorado. Temperature extremes range from -15 to $30^{\circ} \mathrm{C}$ ( 5 to $86^{\circ} \mathrm{F}$ ) with average temperatures ranging from -4 to $18^{\circ} \mathrm{C}\left(25\right.$ to $\left.64^{\circ} \mathrm{F}\right)$

- Non-pressurized "feeder aircraft" typically fly at approximately $3,963 \mathrm{~m}$ to $4,877 \mathrm{~m}(13,000$ to $16,000 \mathrm{ft})$. The highest recorded altitude in a nonpressurized feeder aircraft was 6,017 $\mathrm{m}(19,740 \mathrm{ft})$. Temperatures ranged from approximately -4 to $24^{\circ} \mathrm{C}$ (25 to $\left.75^{\circ} \mathrm{F}\right)$.

Based on these findings, it is evident that packaged products transported by the feeder aircraft network used by cargo carriers like United Parcel Service, Federal Express, and United States Postal Service are liable to experience altitudes as high as $6,100 \mathrm{~m}(20,000 \mathrm{ft})$. Packages transported on the ground may experience altitudes as high as $3,658 \mathrm{~m}$ $(12,000 \mathrm{ft})$ when shipped over mountain passes in the United States. When exposed to these conditions, products and/or packages may be adversely affected by the changes in pressure and temperature.

In an attempt to create a laboratory test method that replicates the environment, ASTM developed and approved a new test method, D6653-01": "Standard Test Methods for Determining the Effects of High Altitude on Packaging Systems by Vacuum Method". The test method recommends that the package be subjected to a reduced pressure of $59.5 \mathrm{kPa}$ representing an altitude of $4,267 \mathrm{~m}(14,000$ ft.) for 60 minutes. There are other test methods used by Department of Transportation (DOT) and International Civil Aviation Organization (ICAO). The problem with all of these existing test methods is that they do not consider the combined effects of pressure, temperature and vibration. Furthermore, the existing DOT specification for shipping and handling HazMat containers requires that the packages be placed with the closure facing up at all times. While this practice is usually followed for ground 
shipments, it is difficult to control in air transport. Air shipments are generally "cubed out" and therefore packages are placed in the orientation most likely to provide the highest volume efficiency. In previous studies $^{5.6}$ there is a clear indication that single parcels get exposed to impacts and vibration in all orientations during handling, sorting, and transportation. The result is that these performance tests often lead to validating packages that have problems in real life shipments.

The purpose of this study was to investigate the effects of vibration alone, altitude alone, and vibration in combination with altitude on the performance of UN approved HazMat packages containing liquids placed in the sideways and upside down orientations. Temperature effects were not considered because it is difficult to do so (in combination with vacuum and vibration) and because the shipping temperatures found in the UPS study $(25-75 \mathrm{~F})$ were not thought to be significant. Furthermore, lowering the temperature of a test package acts to reduce the headspace air pressure, which lowers the pressure differential and makes altitude effects less severe. Testing was therefore done at room temperature to incorporate a small safety factor. Testing was done in five phases. Each test phase represents different combinations of low pressure and vibration that packages are likely to be exposed to during high altitude shipments. Based on the results, a new test method will be proposed to ASTM for the testing of packages that undergo high altitude shipments.

\section{Materials and Test Methods}

Samples of UN approved HazMat packages were procured by Michigan State University from three leading HazMat packaging suppliers. The test packages were certified to meet both the UN/ ICAO and applicable US DOT requirements. The confidentiality of the package suppliers was maintained for the study at the request of the sponsoring agencies. Table 2 shows package types tested during the different phases of the study. The HazMat packages ranged in capacity from 4 oz. to 0.5 gallons. In addition to these HazMat packages, two test packages were prepared that consisted of glass test tubes with rubber stoppers. PACK 1 and PACK 2 are glass test tubes with rubber stoppers, but PACK 1 has tape wrapped around the stopper and test tube in the neck area. These were tested to address concerns over "frictiontype" closures. The test tubes hold approximately $10 \mathrm{ml}$ of liquids.

When performing vibration tests, a decision must be made regarding the severity of the environment. ASTM D $4169^{7}$ describes three different test levels (Assurance Levels I, II and III) for evaluating shipping container performance. These test levels are related to uncertainties in environmental conditions. Assurance Level I corresponds to a high level of abuse, but has a low probability of occurrence. This leads many people to consider Assurance Level I as conservative, with plenty of safety factor built in. Upon consultation with the FAA and DOT, and from past experiences with various tests, a decision was made to use Assurance Level II for this project. Assurance level II is also the most commonly used test level by testing facilities. The five test phases are described below.

\section{Phase I (Truck/Air Vibration and Vacuum at $4267 \mathrm{~m}(\mathbf{1 4 , 0 0 0} \mathrm{ft}$.))}

This test was designed to replicate feeder aircraft and high altitude ground shipments as closely as possible in a single test. It consisted of simultaneous low pressure representing an altitude of $4,267 \mathrm{~m}$ (14,000 ft.) and random vibration using combined truck/air Power Spectral Density (PSD) data. Figure 2 shows the test setup. The test procedure was as follows. Packages were conditioned at ASTM standard conditions of
$73.4 \pm 3.6^{\circ} \mathrm{F}$ for a minimum of 24 hours before testing.

- The primary containers were filled to the recommended fill-level with water and the recommended application torque was applied to the closure.

- Secondary packaging was applied, as if preparing for shipment, in accordance with the manufacturer's instructions.

- Two samples of each stock keeping unit (SKU) were used for this phase.

- The test specimen was placed upside down in the vacuum chamber and the vacuum chamber was placed on an electro-hydraulic vibration table.

- After sealing the vacuum chamber, the vacuum pump was turned on and adjusted to reduce the pressure at a rate of 305 meters (1000 ft.) in 30-60 seconds as recommended in ASTM D6653-01. This replicates normal take off conditions on an airplane of $1000-2000$ feet/minute.

- A vacuum of $59.5 \mathrm{kPa}$ (pressure equivalent of 14,000 feet) was achieved with a permissible error of $\pm 2 \%$.

- While maintaining a vacuum of 59.5 $\mathrm{kPa}$, the vibration table was operated for 30 minutes in the random mode under the combined truck/air shipping environment (Assurance level II, ASTM D 4169), representing shipments of 250 miles.

- After 30 minutes, the chamber inlet valve was opened and the vacuum was released at a rate of 305 meters (1000 ft.) in 30-60 seconds, simulating normal descent conditions.

- The test specimen was removed and any leakage was recorded.

- The closures were removed using a torque tester and the removal torques were measured and recorded.

Some of the results of the Phase I test are shown in Figures 3-8 and Tables 35. Figures 3-4 show that large closures had a greater tendency to leak compared to smaller ones. Tables 3-5 show that 15 out of 32 packages tested leaked. Both 
friction-type closures failed.

\section{Phase II (Truck/Air Vibration Only)}

The purpose of this test was to remove the pressure differential in order to study the effect of vibration only. So the test procedure was exactly the same as in Phase I but with the vacuum chamber steps omitted. An additional step not done in Phase I was to place alignment marks on the container and closure to see if the closures were backing off. This was not found in any of the tests, including Phases III-V that follow, probably because tape was applied around the closure after it was torqued on, as recommended by the manufacturer. Only packages shown in Table 3 were tested in this phase and the test phases that follow. The results of the Phase II tests are shown in Table 6 . There were only 2 leakers out of the 14 tested, compared to 7 out of the same 14 in Phase I (Table 3). Only one of the friction-type closures failed compared to 2 in Phase I. These results clearly show the influence of pressure differential.

\section{Phase III (Vacuum Only at at 4,267 m (14,000 ft.))}

The purpose of this test was to remove vibration in order to study the effect of pressure differential only. So the test procedure was exactly the same as in Phase I, but with vibration related steps omitted. The results are shown in Table 7. There were no leakers, indicating that vibration is a necessary component for failure.

\section{Phase IV (Truck/Air Vibration and Vacuum at 2,438 $\mathrm{m}(8,000 \mathrm{ft})$.}

The purpose of this test was to subject the test package to lower altitudes, but for longer times in order to recreate the environments found in pressurized cargo holds of large commercial aircraft on long flights. The procedure was the same as in Phase I, except that the test pressure was $75.3 \mathrm{kPa}$ instead of 59.5
$\mathrm{kPa}$, simulating $8,000 \mathrm{ft}$. instead of $14,000 \mathrm{ft}$. In addition, the vibration table was operated for 3 hours instead of 30 minutes, as recommended in ASTM D4169. The results are shown in Table 8. There were 4 leakers out of 14 tested. These results are between those of Phase I ( 7 out of 14) and Phase II ( 2 out of 14), which had the same vibration environment but with lower and higher pressures respectively. Test time does not appear to influence the results as much as test pressure.

\section{Phase V (Truck Vibration Only and Vacuum at $2,438 \mathrm{~m}(8,000 \mathrm{ft}$.)}

The purpose of this test was to remove the air transport PSD data from the vibration test spectrum to see if there was any difference in pure ground transport and combined ground/air transport, both at $8000 \mathrm{ft}$. So the test procedure was exactly the same as in Phase IV, but with only the truck PSD data. The results are shown in Table 9. There were 3 leakers out of 14 , one less than in Phase IV and one more than Phase II.

\section{Discussion}

Table 10 summarizes the results of the five different tests on the packages in Table 3. By comparing the data in pairs of rows in Table 10 , the following conclusions were drawn. These conclusions are of course biased toward the sample set of packages studied, but they are believed to be true of packages in general.

- Vibration alone did produce leakers $\left(2^{\text {nd }}\right.$ row in Table 10$)$, but altitude alone did not ( $1^{\text {st }}$ row).

- Altitude is much more important than test time ( $4^{\text {th }}$ versus $5^{\text {th }}$ row).

- High altitude is much worse than low altitude $\left(2^{\text {nd }}\right.$ versus $5^{\text {th }}$ row).

- Combined truck/air vibration is worse than truck alone ( $3^{\text {rd }}$ versus $4^{\text {th }}$ row).

The torque data in Tables 3-9 do not show any correlation between leakers and loss of application torque. It is normal for the removal torque to be some- what less than the application torque. It was expected however that leakers would be the result of the cap backing off or the liner failing in some way, which would show up as an exaggerated loss in torque. But this did not happen. The mechanism responsible for leaks must therefore be something else.

The most likely cause of leaks is localized compression of the liner. When the container is turned upside down and vibrated, it has a tendency to tilt to one side. The live load consisting of the weight of the package bouncing up and down on the closure compresses the liner on one side as shown in Figure 9. This has the effect of squeezing the liner more on this side than the other. The extra amount of compression depends on how large the live load is, and how long it lasts. Truck trailers typically vibrate up and down on the order of five cycles per second with an average glevel of 0.5 during vibration ${ }^{8}$. This means the live load ranges between $50 \%$ above and $50 \%$ below the static weight each cycle of vibration ( 0.2 seconds).

No matter how large the live load is, or how long it lasts, the net effect of vibration is to compress and then uncompress the liner in rapid succession. This can easily render the seal force temporarily zero at isolated locations. A rapid removal of the compression force, such as occurs naturally during vibration, does not allow the liner to recover in time. It takes several seconds, even minutes, for most liners to spring back after indentation. But once the live load is removed, the cap springs back immediately because it is made of a much harder plastic or metal material. All during the time that the cap has sprung back, the liner is recovering, so there is a closing gap between the two. The size of the gap depends on the type of liner and closure. Regardless, however, it represents an opportunity for a leak.

The fact that large closures tend to leak more than small ones is related to 
two independent effects. The first is the pressure differential itself. As the external pressure is reduced, the air trapped inside the container finds it easier to push the cap out. The force tending to push the closure off the container is the area of the cap multiplied by the pressure differential. The area of the cap increases as the square of the diameter, so doubling the cap diameter quadruples the force for a given pressure differential. Larger caps also tend to distort more easily. This, combined with the increased force, can cause the cap to "dome", which in turn allows the liner to raise up a little, making it easier for vibration to create gaps between the liner and the rim of the container.

Large closures may also tend to leak more because of the industry practice for specifying application torques: the recommended application torque in inch-lbs is half the diameter of the closure in millimeters". So a 1 inch $(25.4 \mathrm{~mm})$ closure would have an application torque of 12.7 in-lbs. The manufacturers' recommended application torques for the closures used in this study appeared to follow this practice almost without exception. The problem with this rule is that it leads to larger liners being compressed less than smaller ones for the following reasons. The sealing force, which is the force pressing the liner against the rim of the bottle is approximately ${ }^{10}$

$$
S=\frac{T}{\mu . D}
$$

$$
\text { where, } \begin{aligned}
S & =\text { seal force }(\mathrm{lb}) \\
D= & \text { cap diameter }(\mathrm{in}) \\
T= & \text { application torque (in-lb) } \\
\bar{\mu}= & \text { average coefficient of static } \\
& \text { friction between all sliding } \\
& \text { surfaces }
\end{aligned}
$$

A 1 inch closure having a liner for which the coefficient of friction is 0.2 would therefore have a seal force of $12.7 /(0.2 \times 1.0)=63.5 \mathrm{lb}(28.8 \mathrm{~kg})$, if the industry practice for the recommended application torque is followed. This seal force was confirmed experimental$1 y^{10}$. According to the formula, if the recommended application torque is proportional to the diameter, then the sealing force becomes independent of the diameter. So following industry practice leads to the same sealing force for all closure sizes. But this is not what we want because the sealing force is distributed around the rim of the container. The same force distributed over a larger perimeter reduces the stress on the liner. Consequently, larger closures compress the liner less. This makes it easier for vibration to open up gaps.

\section{Conclusions}

The following conclusions can be drawn from the results of this study:

1. The UN approved HazMat packages tested did not prevent leaks under combined vacuum and vibration characteristic of air and high altitude ground shipments.

2. A pressure differential alone does not appear to cause leaks, but vibration alone can. Simultaneous vibration and vacuum testing is therefore necessary to recreate the shipping environment for both air and high altitude ground shipments.

3. Altitude is more important than test time, higher altitude is worse than lower altitude, and combined truck/air vibration is worse than truck alone.

4. An increase in altitude affects larger caps more than smaller ones because the pressure differential acts over a greater area. The potential for leaks is greater for larger caps.

5. The effect of vibration is to subject the liner to intermittent compression loads. If the liner material is slow to recover, and most are, then vibration produces intermittent gaps which open and close at concentrated pressure points, in step with whatever fre- quency the bottle vibrates at during transportation.

6. The shippers of these HazMat packages do appear to be following the industry rule regarding the application torque.

7. The industry rule is equivalent to requiring that the seal force be the same for all bottles, regardless of cap diameter, and this has the consequence of compressing the liner less for larger caps, so larger caps have greater potential for leaks.

\section{References}

1. F. Wybenga, , Air Transport Incident Data \& Analysis of Packaging Failures, Dangerous Goods Panel Meeting Proceedings, Singapore, 14-18 May 2001

2. McLaughlin, J., FAA Report, Package Failure Analysis for HazMat Shipments for 1998-99, Presented at the Annual Consortium of Distribution Packaging Board Meeting, Michigan State University, Fall 2000

3. UPS Study, RR: D10-1013 on Altitude and Temperature - Study of the Feeder Aircraft Network, ASTM D6653-01, ASTM, 2001

4. ASTM D6653-01, "Standard Test Methods for Determining the Effects of High Altitude on Packaging Systems by Vacuum Method", ASTM, 2001

5. Singh, $P . S$, and Cheema, A., "Measurement and Analysis of the Overnight Small Package Shipping Environment for Federal Express and United Parcel Service, Journal of Testing and Evaluation, pp. 205-211, July 1996

6. Newsham, M., Pierce, S.R., and Singh, $P$, "Parcel Labels, Distribution Pose Challenges for Drop Orientation", Packaging Technology and Engineering, pp.30-33, April 1999

7. Annual Book of ASTM Standards, ASTM, Volume 15.09, 2002.

8. Marcondes, J., P. Singh, and G. Burgess, Dynamic Analysis of a Less Than Truck Load Shipment. Paper \#88-WA-EEP-17, ASME, 1989.

9. "Closure Guide", Closure Manufacturers' Association, 2000

10. Pisuchpen, S., "Model for Predicting Application Torque and Removal Torque of a Continuous Thread Closure", Master of Science Thesis, School of Packaging, Michigan State University, 2000 


\section{FIGURES}

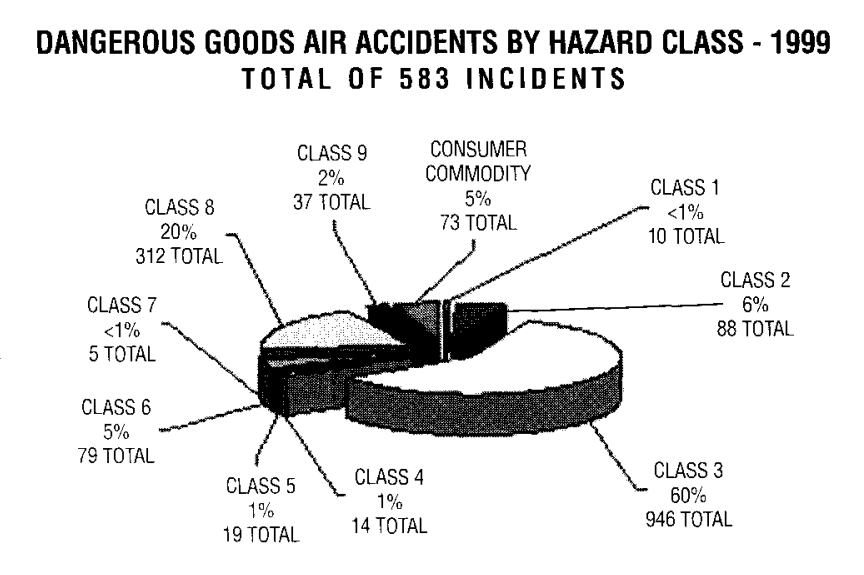

Source: FAA, Office of Aviation Security

Figure 1: Dangerous goods air accidents by hazard class -1999

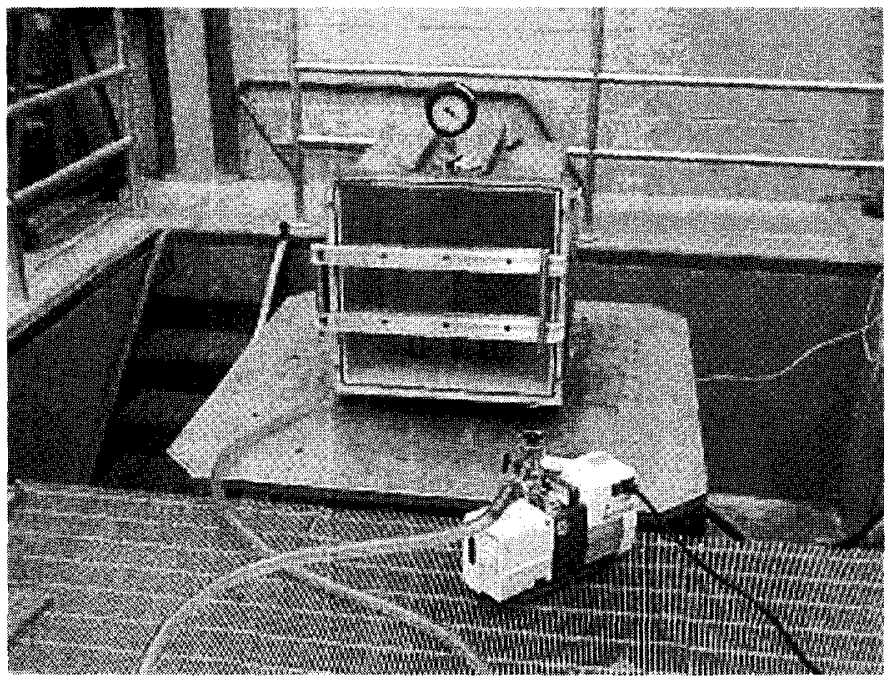

Figure 2: Experimental setup for Phase I

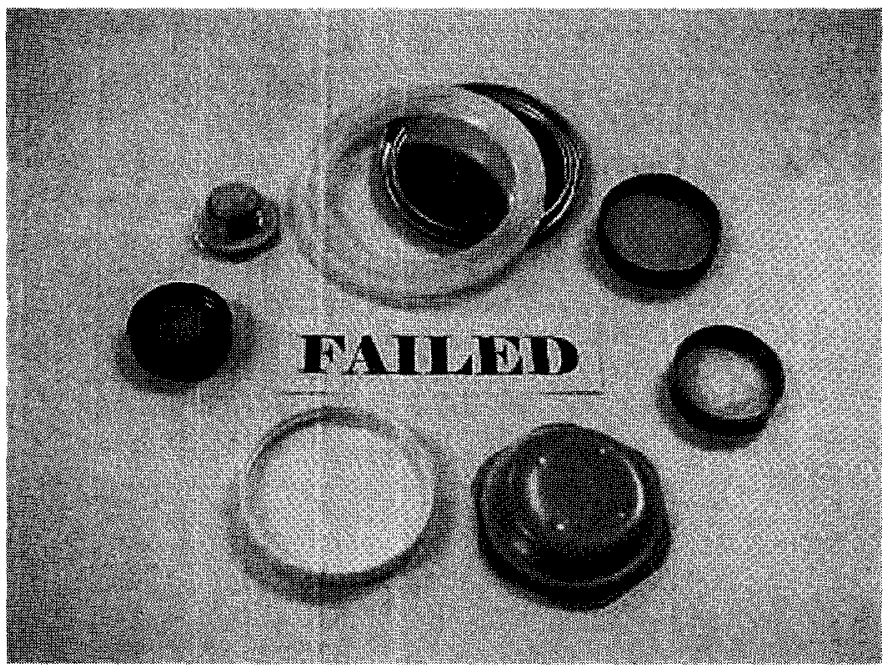

Figure 3: Closures that failed

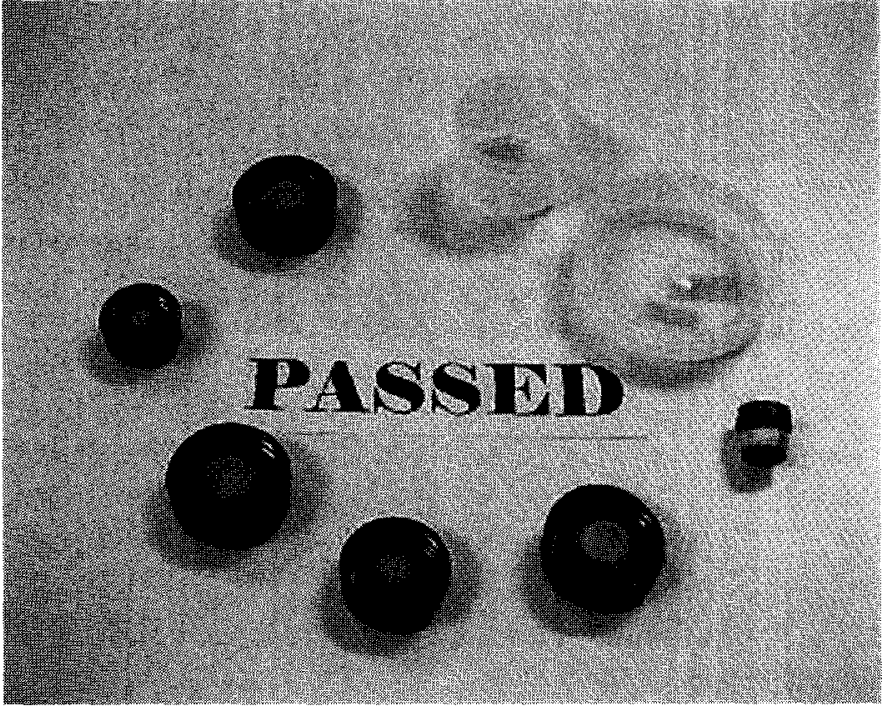

Figure 4: Closures that passed

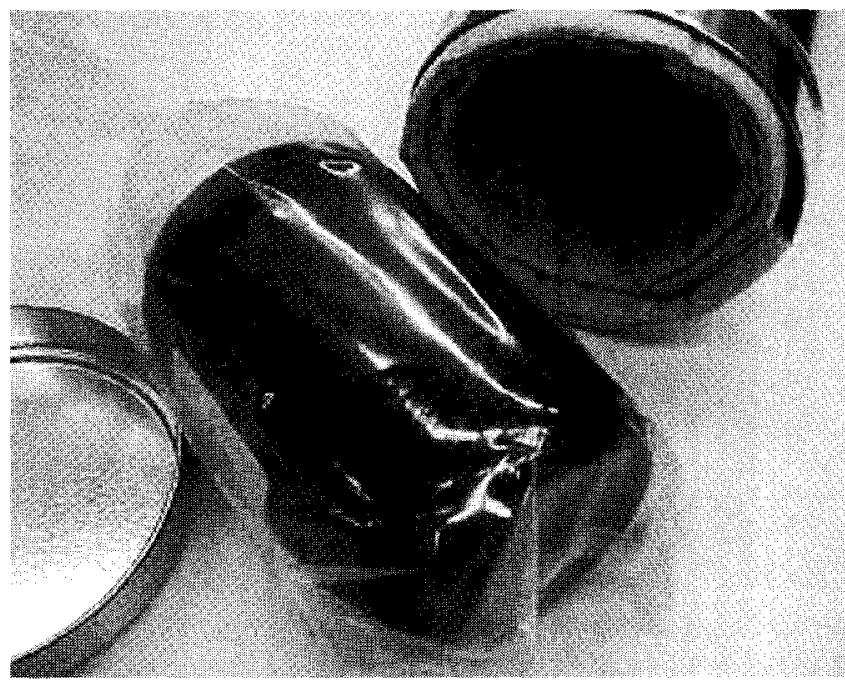

Figure 5: Phase I, UNHWS16

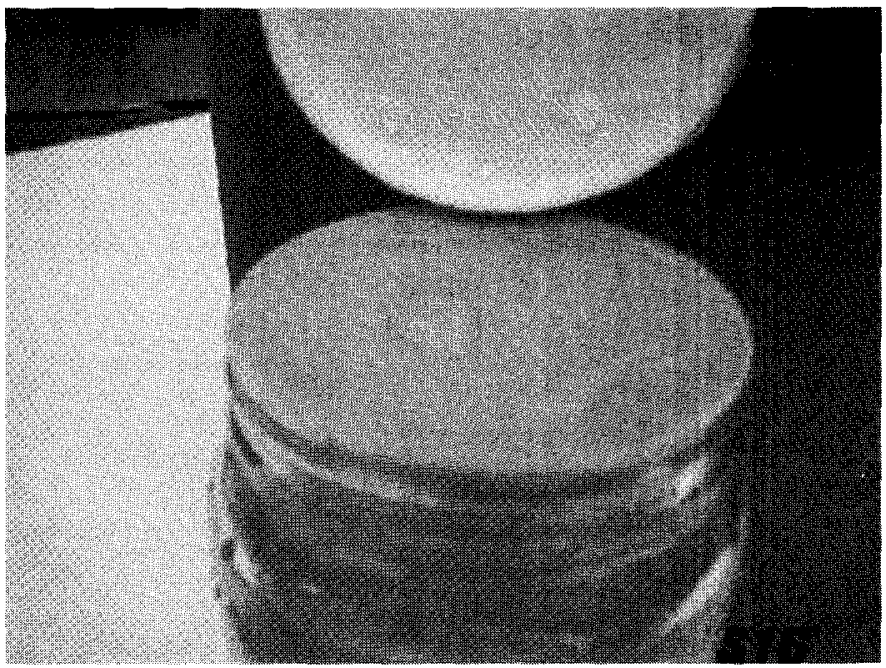

Figure 6: Phase I, UNHWS16 


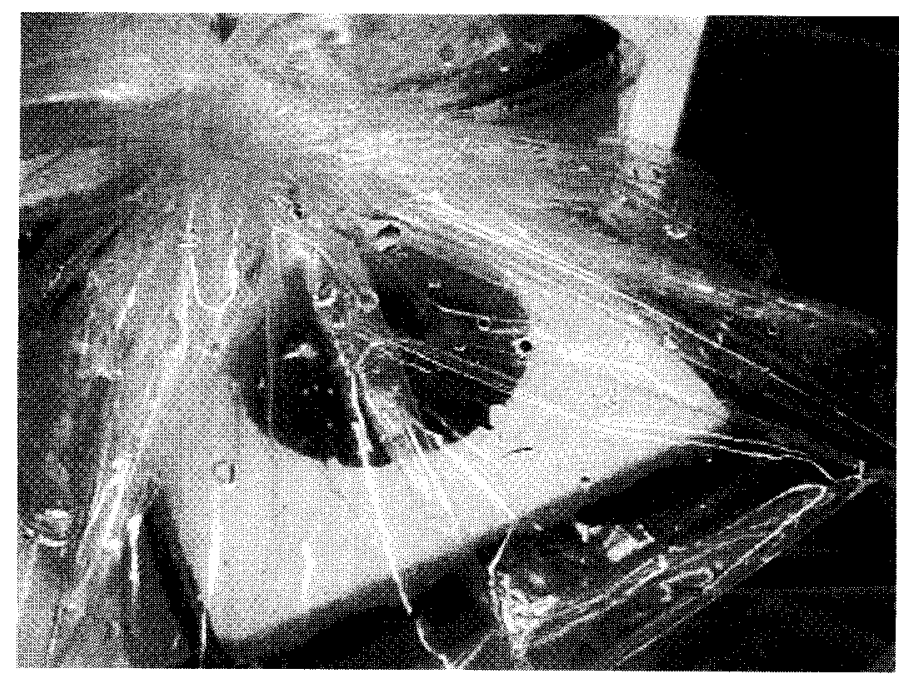

Figure 7: Phase I, UN32PPS

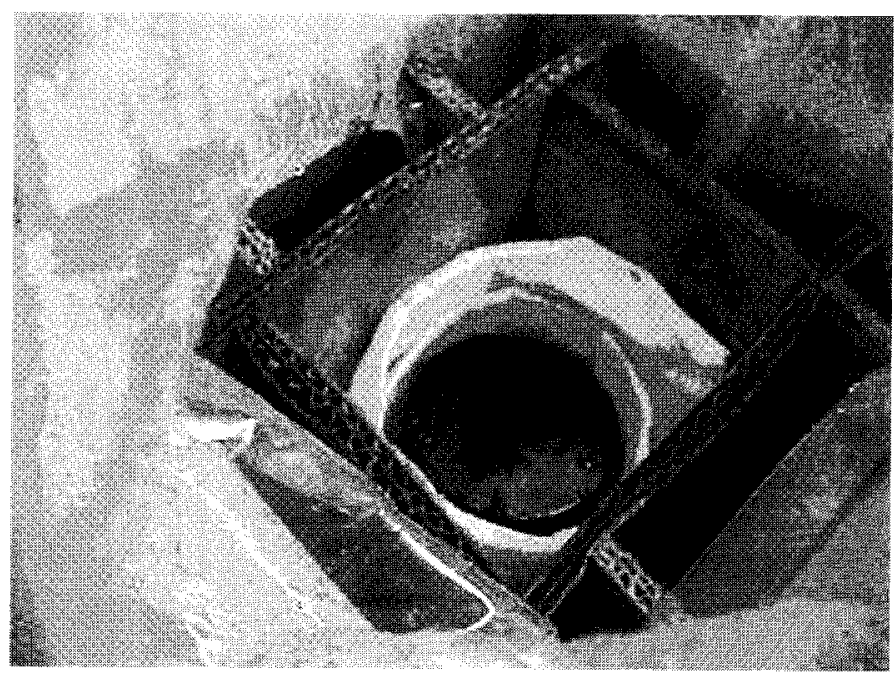

Figure 8: Phase I, CT-SP-0002

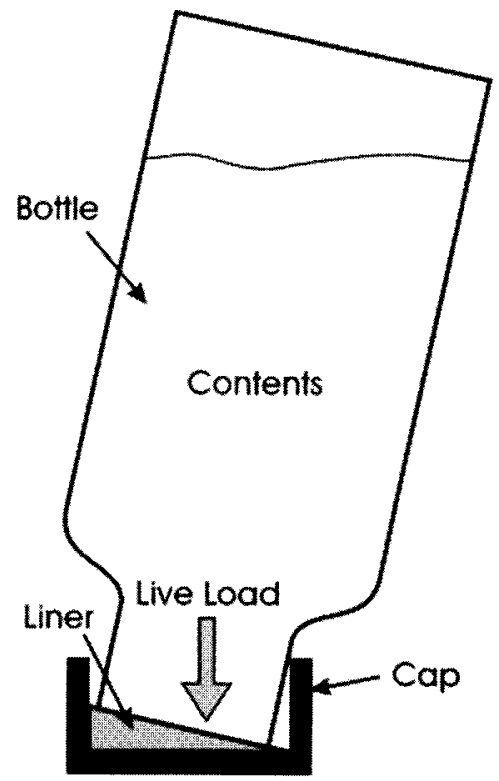

Figure 9: Localized compression of the liner

\section{TABLES}

Table 1: Factors contributing to combination packaging failures

\begin{tabular}{|c|c|c|c|c|c|c|c|c|c|c|c|}
\hline $\begin{array}{c}\text { Packaging } \\
\text { Type }\end{array}$ & $\begin{array}{c}\text { Seal } \\
\text { Closure }\end{array}$ & Unknown & \begin{tabular}{|c|} 
Inner \\
Broken
\end{tabular} & $\begin{array}{l}\text { Punc- } \\
\text { tured }\end{array}$ & $\begin{array}{l}\text { Fork } \\
\text { Lift }\end{array}$ & Seam & $\begin{array}{l}\text { Other } \\
\text { Freight }\end{array}$ & Chime & Drop & $\begin{array}{c}\text { Possible } \\
\text { Drop }\end{array}$ & \\
\hline lastic/4G & $\begin{array}{l}65 \% \\
111\end{array}$ & $3 \%$ & $\begin{array}{l}1 \% \\
2\end{array}$ & $\begin{array}{l}2 \% \\
4\end{array}$ & $\begin{array}{l}3 \% \\
6\end{array}$ & 0 & $5 \%$ & 0 & $\begin{array}{l}9 \% \\
16\end{array}$ & $\begin{array}{l}12 \% \\
20\end{array}$ & 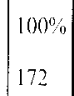 \\
\hline Metal $/ 4 \mathrm{G}$ & $\begin{array}{l}66 \% \\
44\end{array}$ & 3 & 0 & $4 \%$ & $\begin{array}{l}6 \% \\
4\end{array}$ & $\begin{array}{l}4 \% \\
3\end{array}$ & 0 & 0 & \begin{tabular}{l|}
$7 \%$ \\
5
\end{tabular} & $\begin{array}{l}7 \% \\
5\end{array}$ & 67 \\
\hline Glass $/ 4 \mathrm{G}$ & $\begin{array}{l}23 \% \\
15\end{array}$ & $\begin{array}{l}6 \% \\
4\end{array}$ & $\begin{array}{l}17 \% \\
11\end{array}$ & 0 & $\begin{array}{l}5 \% \\
3\end{array}$ & 0 & $1 \%$ & $0 \%$ & $\begin{array}{l}22 \% \\
14\end{array}$ & $\begin{array}{l}25 \% \\
16\end{array}$ & 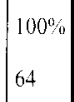 \\
\hline known $4 \mathrm{G}$ & $\begin{array}{l}27 \% \\
8\end{array}$ & $\begin{array}{l}33 \% \\
10\end{array}$ & 0 & 0 & $13 \%$ & 0 & $\begin{array}{l}7 \% \\
2\end{array}$ & 0 & $\begin{array}{l}13 \% \\
4\end{array}$ & $\begin{array}{l}7 \% \\
2\end{array}$ & \\
\hline
\end{tabular}

Source: FAA, Office of Aviation Security

Table 2: Packages tested

\begin{tabular}{|c|l|}
\hline Sujplier & \multicolumn{1}{|c|}{ UN Numbers for Combination Packages Tested } \\
\hline 1 & $\begin{array}{l}\text { HMS-08, UN950PPT, UN950GPT, UN16FFPS, UN32FFPS, UNHWS16, } \\
\text { UN32NPVB, HMSP-32N, UN32PPS, UN4FFPS. UAC32FPS, UN32FAPS }\end{array}$ \\
\hline 2 & UNE151, UN112, UN1541, UN61, UN62. UNIS80, UN51. UN52, UN78, UN79 \\
\hline 3 & $\begin{array}{l}\text { CT-SP-0002, CT-1-92-1000N, CT-1-22-1000-N. V1-0125-N, V1-0500N, V1- } \\
1000 \text { N, V1-0500W }\end{array}$ \\
\hline
\end{tabular}

Table 3: Results for Phase I, Supplier 1

\begin{tabular}{|c|c|c|c|c|c|c|c|c|}
\hline \multirow[t]{4}{*}{ SKU } & \multicolumn{8}{|c|}{ PHASE I } \\
\hline & \multicolumn{4}{|c|}{ SAMPLE A } & \multicolumn{4}{|c|}{ SAMPLE B } \\
\hline & \multicolumn{2}{|c|}{$\mathbf{A T}$} & \multicolumn{2}{|c|}{ RT } & \multicolumn{2}{|c|}{ AT } & \multicolumn{2}{|c|}{ RT } \\
\hline & N.m & lb.in & N.m & Ib.in & N.m & Ith.in & N.m & lb.in \\
\hline HMS-08 & $2.39^{2}$ & $21.2^{\mathrm{L}}$ & $2.18^{2}$ & $19.3^{\mathrm{t}}$ & $2.44^{L}$ & $21.6^{\mathrm{L}}$ & $1.86^{\mathrm{L}}$ & $16.5^{L}$ \\
\hline UN950PPT & 2.27 & 20.1 & 1.75 & 15.5 & 2.26 & 200 & 1.85 & 16.4 \\
\hline UN950GPT & $1.26^{1}$ & $11.2^{\mathrm{L}}$ & $1.24^{2}$ & $11.0^{\mathrm{L}}$ & 1.25 & 111 & 0.91 & 8.1 \\
\hline UN16FFPS & 1.26 & 11.2 & 1.13 & 10.0 & 1.25 & 11.1 & 0.99 & 8.8 \\
\hline UN32FFPS & 1.84 & 16.3 & 1.45 & 12.8 & 1.84 & 16.3 & 1.46 & 12.9 \\
\hline UNHWS16 & $3.97^{\mathrm{L}}$ & $35.2^{\mathrm{L}}$ & $3.56^{2}$ & $315^{\mathrm{L}}$ & $3.96^{1}$ & $35.1^{1}$ & $2.50^{\mathrm{L}}$ & $22.1^{\mathrm{L}}$ \\
\hline UN32NPVB & 6.32 & 56.0 & 4.03 & 357 & 6.37 & 56.4 & 3.68 & 32.6 \\
\hline HMSP-32N & 2.04 & 18.1 & 1.51 & 134 & 20.05 & 18.2 & 1.65 & 14.6 \\
\hline UN32PPS & 2.27 & 20.1 & 2.21 & 19.6 & $2.27^{\mathrm{L}}$ & $20.1^{\text {t. }}$ & $2.16^{\mathrm{I}}$ & $19.1^{2}$ \\
\hline UN4FFPS & 1.25 & 11.1 & 1.12 & 9.9 & 1.28 & 11.3 & 1.04 & 9.2 \\
\hline UAC32FPS & $1.8 \mathrm{I}$ & 16.0 & 1.78 & 15.8 & 1.82 & 16.1 & 1.60 & 14.2 \\
\hline UN32FAPS & 1.26 & 11.2 & 1.04 & 9.2 & $1.28^{1 .}$ & $11.3^{\mathrm{L}}$ & $0.85^{\mathrm{L}}$ & $7.5^{\mathrm{L}}$ \\
\hline PACK 1 & & & & & & & & \\
\hline PACK 2 & 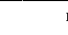 & & & & & & & \\
\hline
\end{tabular}

$\mathrm{AT}=$ Application Torque, $\mathrm{RT}=$ Removal Torque, $\mathrm{L}=$ Leakers

Table 4: Results for Phase I, Supplier 2

\begin{tabular}{|c|c|c|c|c|c|c|c|c|}
\hline \multirow{3}{*}{ SKU } & \multicolumn{9}{|c|}{ PHASE I } \\
\cline { 2 - 9 } & \multicolumn{3}{|c|}{ SAMPLE A } & \multicolumn{3}{c|}{ SAMPLE B } \\
\cline { 2 - 9 } & \multicolumn{2}{|c|}{ AT } & \multicolumn{2}{|c|}{ RT } & \multicolumn{3}{c|}{ AT } & \multicolumn{2}{c|}{ RT } \\
\cline { 2 - 9 } & N.m & Ih.in & N.m & Ih.in & N.m & Ib.in & N.m & Ib.in \\
\hline UNE151 & 1.25 & 11.1 & 0.81 & 7.2 & 1.25 & 11.1 & 0.82 & 7.3 \\
\hline UN112 & $2.27^{\mathrm{L}}$ & $20.1^{\mathrm{L}}$ & $2.07^{\mathrm{L}}$ & $18.3^{\mathrm{L}}$ & 2.29 & 20.3 & 2.12 & 18.8 \\
\hline UN1541 & 1.29 & 11.4 & 0.73 & 6.5 & 1.26 & 11.2 & 0.80 & 7.1 \\
\hline UN61 & 2.27 & 20.1 & 1.96 & 17.4 & 2.27 & 20.1 & 2.09 & 18.5 \\
\hline UN 62 & 6.33 & 56.1 & 5.32 & 47.1 & $6.39^{\mathrm{L}}$ & $56.6^{\mathrm{L}}$ & $5.07^{\mathrm{L}}$ & $44.9^{\mathrm{L}}$ \\
\hline UN1S80 & $4.00^{\mathrm{L}}$ & $35.4^{\mathrm{L}}$ & $3.35^{\mathrm{L}}$ & $29.7^{\mathrm{L}}$ & 4.02 & 35.6 & 3.65 & 32.3 \\
\hline UN51 & 1.28 & 11.3 & 0.95 & 8.4 & 1.26 & 11.2 & 0.68 & 6.0 \\
\hline UN52 & 1.82 & 16.1 & 1.70 & 15.1 & 1.82 & 16.1 & 1.51 & 13.4 \\
\hline UN78 & $3.96^{\mathrm{L}}$ & $35.1^{\mathrm{L}}$ & $3.18^{\mathrm{L}}$ & $30.8^{\mathrm{L}}$ & $3.96^{\mathrm{L}}$ & $35.1^{\mathrm{L}}$ & $3.62^{\mathrm{L}}$ & $32.1^{\mathrm{L}}$ \\
\hline UN79 & 3.96 & 35.1 & 3.59 & 31.8 & $3.99^{1 .}$ & $35.3^{\mathrm{L}}$ & $3.70^{\mathrm{L}}$ & $32.8^{\mathrm{L}}$ \\
\hline
\end{tabular}

AT $=$ Application Torque, $\mathrm{RT}=$ Removal Torque, $\mathrm{L}=$ Leakers 
Table 5: Results for Phase I, Supplier 3

\begin{tabular}{|c|c|c|c|c|c|c|c|c|}
\hline \multirow[t]{4}{*}{ SKU } & \multicolumn{8}{|c|}{ PHASE I } \\
\hline & \multicolumn{4}{|c|}{ SAMPLE A } & \multicolumn{4}{|c|}{ SAMPLE B } \\
\hline & \multicolumn{2}{|c|}{$\mathbf{A T}$} & \multicolumn{2}{|c|}{ RT } & \multicolumn{2}{|c|}{ AT } & \multicolumn{2}{|c|}{ RT } \\
\hline & N.m & lb, in & N.m & Lb.in & N.m & lb.in & N.m & lb.in \\
\hline CT-SP-0002 & 2.39 & 21.2 & 2.17 & 19.2 & 2.39 & 21.2 & 2.24 & 19.8 \\
\hline CT-1-92-1000-N & 3.77 & 33.4 & 2.31 & 20.5 & 3.79 & 33.6 & 2.44 & 21.6 \\
\hline CT-1-92-1000-W & $6.34^{L}$ & $56.2^{\mathrm{L}}$ & $3.65^{\mathrm{L}}$ & $32.3^{2}$ & 6.45 & 57.1 & 4.14 & 36.7 \\
\hline CT-4-92-1000-N & 3.74 & 33.1 & 2.04 & 18.1 & $3.75^{L}$ & $33.2^{\mathrm{L}}$ & $1.89^{\mathrm{L}}$ & $16.7^{2}$ \\
\hline $\mathrm{V} 1-0125-\mathrm{N}$ & 1.30 & 11.5 & 1.12 & 9.9 & 1.25 & 11.1 & 1.04 & 9.2 \\
\hline V1-0500N & 1.29 & 11.4 & 1.11 & 9.8 & 1.25 & 11.1 & 1.04 & 9.2 \\
\hline $\mathrm{V} 1-1000 \mathrm{~N}$ & 2.30 & 20.4 & 1.19 & 10.5 & 2.27 & 20.1 & 1.65 & 14.6 \\
\hline $\mathrm{V} 1-0500 \mathrm{~W}$ & $3.97^{\mathrm{l}}$ & $35.2^{\mathrm{L}}$ & $3.18^{2}$ & $28.2^{\mathrm{L}}$ & $3.99^{2}$ & $35.3^{\mathrm{L}}$ & $2.57^{\mathrm{L}}$ & $22.8^{\mathrm{L}}$ \\
\hline
\end{tabular}

$\mathrm{AT}=$ Application Torque, $\mathrm{RT}=$ Removal Torque, $\mathrm{L}=$ Leakers

Table 6: Results for Phase II

\begin{tabular}{|c|c|c|c|c|c|c|c|c|}
\hline \multirow[t]{4}{*}{ SKU } & \multicolumn{8}{|c|}{ PHASE II } \\
\hline & \multicolumn{4}{|c|}{ SAMPLE A } & \multicolumn{4}{|c|}{ SAMPLE B } \\
\hline & \multicolumn{2}{|c|}{$\mathrm{AT}$} & \multicolumn{2}{|c|}{ RT } & \multicolumn{2}{|c|}{ AT } & \multicolumn{2}{|c|}{ RT } \\
\hline & N.m & lh.in & N.m & lb.in & N.m & lb.in & $\mathrm{N} . \mathrm{m}$ & lb.in \\
\hline HMS- 08 & 2.38 & 21.1 & 2.24 & 19.8 & 2.39 & 21.2 & 2.20 & 19.5 \\
\hline UN950PPT & 2.31 & 20.5 & 2.05 & 18.2 & 2.31 & 20.5 & 2.13 & 18.9 \\
\hline UN950GPT & 1.28 & 11.3 & 1.22 & 10.8 & 1.26 & 11.2 & 1.15 & 10.2 \\
\hline UN16FFPS & 1.25 & 11.1 & 1.11 & 9.8 & 1.25 & 11.1 & 1.07 & 9.5 \\
\hline UN32FFPS & 1.82 & 16.1 & 1.56 & 13.8 & 1.81 & 16.0 & 1.52 & 13.5 \\
\hline UNHWS 16 & 3.99 & 35.3 & 3.13 & 27.7 & 3.96 & 35.1 & 3.51 & 31.1 \\
\hline UN32NPVB & 6.40 & 56.7 & 5.04 & +4.6 & 6.36 & 56.3 & 5.39 & 47.7 \\
\hline HMSP-32N & 2.07 & 18.3 & 1.81 & 160 & 2.07 & 18.3 & 1.65 & 146 \\
\hline UN32PPS & $2.26^{\mathrm{L}}$ & $20.0^{L}$ & $2.00^{\mathrm{L}}$ & $17.7^{\mathrm{L}}$ & 2.29 & 20.3 & 2.00 & 17.7 \\
\hline UN4FFPS & 1.25 & 11.1 & 1.16 & 10.3 & 1.30 & 11.5 & 1.14 & 10.1 \\
\hline UAC32FPS & 1.81 & 16.0 & 1.49 & 1.3 .2 & 1.82 & 16.1 & 1.55 & 13.7 \\
\hline UN32FAPS & 1.25 & 11.1 & 1.15 & 10.2 & 1.26 & 11.2 & 1.11 & 9.8 \\
\hline PACK 1 & & & & & & & & \\
\hline PACK 2 & & & & & & & & \\
\hline
\end{tabular}

$\mathrm{AT}=$ Application Torque, $\mathrm{RT}=$ Removal Torque, $\mathrm{L}=$ Leakers

Table 7: Results for Phase III

\begin{tabular}{|l|c|c|c|c|c|c|c|c|}
\hline \multirow{4}{*}{ SKU } & \multicolumn{9}{|c|}{ PHASE III } \\
\cline { 2 - 10 } & \multicolumn{3}{|c|}{ SAMPLE A } & \multicolumn{3}{c|}{ SAMPLE B } \\
\cline { 2 - 10 } & \multicolumn{2}{|c|}{ AT } & \multicolumn{2}{|c|}{ RT } & \multicolumn{2}{c|}{ AT } & \multicolumn{2}{c|}{ RT } \\
\cline { 2 - 10 } & N.m & Ib.in & N.m & Ih.in & N.m & Ib.in & N.m & Ib.in \\
\hline HMS-08 & 2.39 & 21.2 & 2.07 & 18.3 & 2.39 & 21.2 & 1.92 & 17.0 \\
\hline UN950PPT & 2.26 & 20.0 & 2.01 & 17.8 & 2.27 & 20.1 & 1.94 & 17.2 \\
\hline UN950GPT & 1.25 & 11.1 & 1.15 & 10.2 & 1.26 & 11.2 & 1.21 & 10.7 \\
\hline UN16FFPS & 1.25 & 11.1 & 0.99 & 8.8 & 1.25 & 11.1 & 1.04 & 9.2 \\
\hline UN32FFPS & 1.84 & 16.3 & 1.60 & 14.2 & 1.81 & 16.0 & 1.67 & 14.8 \\
\hline UNHWS16 & 4.01 & 35.5 & 3.24 & 28.7 & 4.01 & 35.5 & 3.61 & 32.0 \\
\hline UN32NPVB & 6.33 & 56.1 & 4.55 & 40.3 & 6.36 & 56.3 & 5.20 & 46.1 \\
\hline HMSP-32N & 2.04 & 18.1 & 1.59 & 14.1 & 2.03 & 18.0 & 1.54 & 13.6 \\
\hline UN32PPS & 2.28 & 20.2 & 2.00 & 17.7 & 2.27 & 20.1 & 2.00 & 17.7 \\
\hline UN4FFPS & 1.25 & 11.1 & 1.23 & 10.9 & 1.26 & 11.2 & 1.24 & 11.0 \\
\hline UAC32FPS & 1.81 & 16.0 & 1.78 & 15.8 & 1.82 & 16.1 & 1.72 & 15.2 \\
\hline UN32FAPS & 1.25 & 11.1 & 1.22 & 10.8 & 1.25 & 11.1 & 1.23 & 10.9 \\
\hline PACK 1 & & & & & & & & \\
\hline PACK 2 & & & & & & & & \\
\hline
\end{tabular}

AT = Application Torque, $\mathrm{RT}=$ Removal Torque, $\mathrm{L}=$ Leakers
Table 8: Results for Phase IV

\begin{tabular}{|c|c|c|c|c|c|c|c|c|}
\hline \multirow[t]{4}{*}{ SKU } & \multicolumn{8}{|c|}{ PHASEIV } \\
\hline & \multicolumn{4}{|c|}{ SAMPLE A } & \multicolumn{4}{|c|}{ SAMPLE B } \\
\hline & \multicolumn{2}{|c|}{ AT } & \multicolumn{2}{|c|}{ RT } & \multicolumn{2}{|c|}{ AT } & \multicolumn{2}{|c|}{ RT } \\
\hline & N.m & Ib.in & $\mathrm{N} . \mathrm{m}$ & lb.in & $\mathrm{N} . \mathrm{m}$ & lb.in & N.m & lb.in \\
\hline HMS-08 & 2.39 & 21.2 & 2.21 & 19.6 & 2.4 & 21.6 & 2.09 & 18.5 \\
\hline UN950PPT & $2.27^{\mathrm{L}}$ & $20.1^{\mathrm{L}}$ & $2.10^{\mathrm{I}}$ & $18.6^{2}$ & 2.29 & 20.3 & 2.24 & 19.8 \\
\hline UN950GPT & $1.26^{\mathrm{L}}$ & $11.2^{\mathrm{L}}$ & $0.41^{1}$ & $3.6^{1}$ & 1.25 & 11.1 & 1.04 & 9.2 \\
\hline UN16FFPS & 1.30 & 11.5 & 1.24 & 11.0 & 1.28 & 11.3 & 1.23 & 10.9 \\
\hline UN32FFPS & 1.82 & 16.1 & 1.78 & 15.8 & 1.85 & 16.4 & 1.74 & 15.4 \\
\hline UNHWS 16 & $3.97^{L}$ & $35.2^{2}$ & 3.18 & $28.2^{\mathrm{L}}$ & $+.02^{\mathrm{L}}$ & $35.6^{2}$ & $3.61^{1}$ & $32.0^{L}$ \\
\hline UN32NPVB & 6.34 & 56.2 & +.02 & 35.6 & 6.32 & 5600 & 4.34 & 38.4 \\
\hline HMSP-32N & 2.04 & 18.1 & 1.51 & 13.4 & .2 .03 & 180 & 1.38 & 12.2 \\
\hline UN 32 PPS & 2.29 & 20.3 & 2.24 & 19.8 & 2.26 & 20.0 & 1.90 & 16.8 \\
\hline UN4FFPS & 1.25 & 11.1 & 1.23 & 10.9 & 1.26 & 11.2 & 1.16 & 10.3 \\
\hline UAC32FPS & 1.82 & 16.1 & 1.60 & $1+2$ & 183 & 16.2 & 1.41 & 12.5 \\
\hline UN32FAPS & 1.26 & 11.2 & 1.23 & 10.9 & 1.28 & 11.3 & 1.22 & 10.8 \\
\hline PACK 1 & & & & & & & & \\
\hline PACK 2 & & & & & & & & \\
\hline
\end{tabular}

$\mathrm{AT}=$ Application Torque, $\mathrm{RT}=$ Removal Torque, $\mathrm{L}=$ Leakers

Table 9: Results for Phase V

\begin{tabular}{|c|c|c|c|c|c|c|c|c|}
\hline \multirow[t]{4}{*}{ SKU } & \multicolumn{8}{|c|}{ PHASE V } \\
\hline & \multicolumn{4}{|c|}{ SAMPLE A } & \multicolumn{4}{|c|}{ SAMPLE B } \\
\hline & \multicolumn{2}{|c|}{ AT } & \multicolumn{2}{|c|}{ RT } & \multicolumn{2}{|c|}{$\mathrm{AT}$} & \multicolumn{2}{|c|}{ RT } \\
\hline & N.m & Ib.in & N.m & 1b.in & N.m & Ib.in & $\mathrm{N} \cdot \mathrm{m}$ & Ib.in \\
\hline HMS-08 & $2.38^{2}$ & $21.1^{t}$ & $1.95^{2}$ & $17.3^{\mathrm{I}}$ & 2.38 & 21.1 & 1.78 & -15.8 \\
\hline UN950PPT & 2.26 & 20.0 & 1.98 & 17.5 & 2.29 & 20.3 & 1.85 & 16.4 \\
\hline UN950GPT & 1.25 & 11.1 & -1.22 & 108 & 1.24 & 11.0 & 1.15 & 10.2 \\
\hline UN16FFPS & 1.25 & 11.1 & 1.15 & 10.2 & 1.26 & 11.2 & 1.19 & 10.5 \\
\hline UN32FFPS & 1.81 & 160 & 1.67 & 14.8 & 1.82 & 16.1 & 1.72 & 15.2 \\
\hline UNHWS16 & $3.96^{1}$ & $35.1^{\mathrm{L}}$ & $3.56^{2}$ & $31.5^{-2}$ & 3.97 & 35.2 & 3.40 & 30.1 \\
\hline UN32NPVB & 6.33 & 56.1 & -4.39 & 38.9 & 6.37 & 56.4 & 4.54 & 40.2 \\
\hline HMSP-32N & 2.03 & 18.0 & 1.61 & 14.3 & 2.07 & 18.3 & 1.90 & 16.8 \\
\hline UN 32 PPS & 2.29 & 20.3 & 1.94 & 17.2 & 2.30 & 20.4 & 2.12 & 18.8 \\
\hline UN4FFPS & 1.25 & 11.1 & 1.16 & 10.3 & 1.28 & 11.3 & 1.17 & 10.4 \\
\hline UAC32FPS & 1.81 & 16.0 & 1.64 & 145 & 1.83 & 16.2 & 1.69 & 15.0 \\
\hline UN 32 FAPS & 1.24 & 11.0 & 1.11 & 9.8 & 1.25 & 11.1 & 1.15 & 10.2 \\
\hline PACK 1 & & & & & & & & \\
\hline & & & & & & & & \\
\hline
\end{tabular}

AT $=$ Application Torque, $\mathrm{RT}=$ Removal Torque, $\mathrm{L}=$ Leakers

Table 10: Ranking of Environments

\begin{tabular}{|c|c|}
\hline Conditions & $\begin{array}{c}\text { Number of Leakers out of 14 Packages } \\
\text { Tested }\end{array}$ \\
\hline $\begin{array}{c}\text { No Vibration } \\
14,000 \mathrm{ft} \\
30 \text { minutcs }\end{array}$ & 0 \\
\hline $\begin{array}{c}\text { Truck and Air Vibration } \\
0 \mathrm{ft} \\
30 \text { minutes }\end{array}$ & \\
\hline $\begin{array}{c}\text { Truck Only Vibration } \\
8000 \mathrm{ft} \\
180 \text { minutcs }\end{array}$ & \\
\hline $\begin{array}{c}\text { Truck and Air Vibration } \\
8000 \mathrm{ft} \\
180 \text { minutes }\end{array}$ & \\
\hline $\begin{array}{c}\text { Truck and Air Vibration } \\
14,000 \mathrm{ft} \\
30 \text { minutcs }\end{array}$ & \\
\hline
\end{tabular}

